\title{
Advocacy for Intersexuality in Chinese Community: Preliminary Effectiveness of Applied Drama for Frontline Professionals
}

\author{
Elaine Yin-Ling Tsui \\ Hong Kong Baptist University, \\ Hong Kong, China
}

\author{
Ginny Man-Ching Tam \\ Hong Kong Drama/Theatre and Education Forum, \\ Hong Kong, China
}

\begin{abstract}
Intersexuality is a general term referring to an individual who is born with a reproductive anatomy that does not fit the typical gender binary system. It has always been a mystery as very little information is currently available to the public in the Chinese community. It leaves society to remain generally ignorant about the existence of individuals with intersex status, and in turn, the fear of stigmatization and exclusion by society compels most affected individuals to conceal their personal information. Since it is often that frontline professionals, including teachers and social workers, are more likely to have direct contact with individual with intersex status, the living experience of affected individuals highly relies on their knowledge and attitudes towards intersex. Using qualitative-quantitative mixed method, this pilot study revealed that most of the frontline professionals possess inadequate knowledge towards intersexuality, let alone the level of competence in handling affected individuals and their families. Furthermore, this study provided preliminary evidence to support the effectiveness of the use of applied drama in cultivating positive change in attitudes towards intersexuality among frontline professionals. These results are expected to inform the development of a competence training program for frontline professionals and to initiate discussion and to raise awareness of intersexuality in Chinese community.
\end{abstract}

Keywords: intersexuality, drama education, professional training, attitudes change

\section{Introduction}

Intersexuality is an umbrella term that refers to the condition in which individuals who are born with ambiguous sex organs or with the sex organs associated with one sex as well as the chromosomes associated with another (DeFrancisco \& Palczewski, 2007). For individuals with intersex status identified in the neonatal period, the conditions varies and ranges from having an ambiguous external genitalia at birth, e.g., congenital adrenal hyperplasia (CAH) or partial androgen insensitivity syndrome, to having discrepancy between the karyotype and phenotype at birth, e.g., complete androgen insensitivity syndrome (CAIS). The intersex condition can also be identified later in life, where the diagnosis is given after the presentation of early puberty during childhood, e.g., CAH; or masculinization in a teenage girl, e.g., testosterone biosynthetic defects; or a girl in her puberty present with primary amenorrhoea (absence of a menstrual period) is found to have an XY karyotype (e.g., CAIS) (Creighton \& Liao, 2004). The prevalence of intersexuality is estimated at 1 in 2000 live

\footnotetext{
*Acknowledgements: This project is funded by Faculty Development Fund (UGC/FDS23/H02/16), University Grants Committee, Hong Kong.

Elaine Yin-Ling Tsui, Ph.D., lecturer, Department of Social Work, Hong Kong Baptist University.

Ginny Man-Ching Tam, deputy manager, Hong Kong Drama/Theatre and Education Forum.
} 
births (Blackless et al., 2000). The diversity of intersexuality makes it impossible to categorize intersexuality as a "third sex". It is rather a term that is used to describe individuals with variation in their sex characteristics. Intersex fails to be seen as part of the human continuum, as this narrow definition prevents individuals with intersex from being treated with respect (Butler, 2004).

\section{Social Stigmatization and Social Exclusion}

Intersexuality has always been a mystery and very few information is currently available to the public. The general public remains ignorant about the existence of individuals with intersex status, and in turn, the fear of stigmatization and exclusion by society compels most individuals with intersex status to conceal any personal information in relation to their sex. As a result, the right to physical autonomy has been ignored and the psychological well-being of these affected individuals remains unexplored and neglected. With the pressing concern on human right issues, the International Lesbian, Gay, Bisexual, Trans and Intersex Association, formerly known as the International Lesbian and Gay Association, was extended to cover concerns on intersexuality in 2009 (International Lesbian Gay Bisexual Trans and Intersex Association, 2010). Therefore, it is not uncommon that intersexuality is associated with lesbian, gay, bisexual and transgender (LGBT). However, unlike lesbians, gays, bisexuals, transgender people, intersexuality is likely to lean on the medical end on the bipolar spectrum of psychological and medical condition scale. Moreover, myths exist and the general public often mistakenly equates intersexuality to transgender. The living experience of individuals with intersex status is heavily influenced by the acceptance of the general population, especially by people who may work closely with them in social service or school settings. Training programs that enhancing positive attitudes facilitating empathy towards intersexuality among frontline professionals have its pressing need.

\section{Applied Theatre}

Applied theatre refers to theatre practice which is taken place in non-theatre setting, such as schools, hospitals or any other location in the community. Some applied theatre is used in school setting to enhance learning experience. Some projects work on social issues or people who are socially excluded (Prentki \& Preston, 2009). There are many conventions under the umbrella of applied theatre. Some of these conventions create theatre experience by engaging audience to participate in a theatrical story. A technique called process drama was applied in this study. In addition, some features of Theatre of the Oppressed, such as Image Theatre, was also used for reflective purposes.

Process drama engages students by interactive and a range of role-play activities in a story. According to O’Neill (1995), “(t)he characters, situations, events and issues that are created and explored within the dramatic world reflect and illuminate the real world" (O’Neill, 1995, p. 152). In the process of playing imaginary roles, students are required to think beyond their own points of view and consider the topic from multiple perspectives. Different from traditional theatre on a stage, process drama requires an acting teacher working with students to create an imaginary dramatic world. This platform helps students to explore a particular problem, situation or theme.

In addition, process drama does not provide scripts for participants to follow. Facilitator only creates a framework but not details of a story. Participants are invited to co-create the scenes using their imagination and own language. These flexibilities offer more autonomy and ownership for the participants in the learning process.

The other convention which is applied in this workshop called Theatre of the Oppressed. It is developed by a Brazilian theatre practitioner, Augusto Boal. According to Boal (1995), Theatre of the Oppressed 
employed physical exercises, theatre games, image and improvisation systematically to turn the use of theatre practice to a tool for understanding social and personal problems. More importantly it develops affective experience through the aesthetic process. The emotional attachment develops a deeper level of understanding of the oppressed protagonist. The technique of Image Theatre under Theatre of the Oppressed is applied in the reflective session of this project.

Image Theatre uses participants' body to express and discusses idea by sculpturing bodies into still images but in the absence of verbal communication (Boal, 2008). These still images can be stimulating because they sometimes visualise abstract concept, especially in the case of oppression. Once the image of oppression is formed, the group can improvise an ideal image without prior verbal discussion. This imaginary process provides an open context for exploring alternative actions symbolically.

\section{Study Aim}

Very little is known in terms of the attitudes of teachers and social workers towards intersexuality in the Chinese community. To this end, a pilot study was required to examine the effectiveness of using applied theatre in improving positive attitudes toward intersexuality. It was hypothesized that, with the use of applied process dramas a primary approach, participants were able to cultivate empathy and positive attitudes by experiencing the psychosocial needs of intersex individuals and their family members.

\section{Methods}

\section{Participants Recruitment and Procedure}

The current qualitative-quantitative mixed study included two half-day training workshops which were held in November 2015 and January 2016. Invitations for the workshop were sent out twice via the local university intranet between September and October 2015, targeting individuals with social work and education background. The workshops were free of charge and were held in the local university for convenience to potential participants. In total, 23 individuals enrolled for the workshops, of which 20 attended. All attendants were invited to complete a set of questionnaire before and immediately after the training workshops. Subsequently, a post-workshop focus group was conducted in January 2016. Among the attendants, 10 were invited to join the focus group interview.

\section{Program Details: The Use of Applied Theatre}

The program was divided into three major parts: (1) introduction and warm up exercises; (2) process drama, which was the core part of the program; and (3) reflective exercises.

Introduction/warm-up exercises. The program started with a brief introduction of the workshop schedule and some basic information about intersex. Warm up exercises followed to help participants to be creative with using their body and space (Clifford \& Herrmann, 1999).

Process drama. The core part of the process drama was about an imaginary character who called Denise. The character of Denise was inspired by an intersex character in a French novel La Tête enbas (Châtelet, 2003). The materials in the novel were not sufficient for developing the character in the process drama. Denise's story was then modified based on research on various lifestory of intersex people in the world. Denise in the process drama was described with symptom similar to congenital adrenal hyperplasia (CAH).

At the beginning of the process drama, participants knew that Denise was an intersex but did not know the details and symptom of Denise. Participants learnt and experienced the challenges of an intersex through 
playing the role of Denise, Denise's family members and friends.

Participants started with reading four short entries of Denise's diary, which only briefly described Denise emotions. The information provided in these entries were incomplete, such as the unknown scar in Denise's body, dislike being forced to wear a skirt, a close relationship with a girl called Jenny and delayed menstruation. All these incomplete information helped to create a very preliminary impression of the character. It also served as a hook to motivate participant actively acquiring the story of Denise (Bundy \& Dunn, 2006; O’Toole \& Dunn, 2002).

The core part of the process drama was divided into eight main parts: (1) Denise's childhood; (2) Denise refused to wear a skirt which is socially expected in a formal event; (3) Denise was having argument with parent(s) regarding the event; (4) Denise was surprised to learn that she was an intersex because of delayed puberty; (5) Denise tried to disclose her news to her closest friend, Jenny; (6) Denise's family discussed the medical treatment without Denise's consensus; (7) Denise engaged in an argument with her mother after discovering her hormone medicine; (8) The death of Denise.

Denise's childhood. Participants were invited to see the belongings of Denise and her friend. Two sets of personal materials were prepared. One set was representing the belongings of Denise, which was very boyish compare to the other set of props. The other set of materials was very colourful, which represented the belongings of a girl friend of Denise. Participants in groups of four were asked to select one of the Denise's items. With that selected item, the groups had to create a still image that happened in Denise daily life.

Denise refused to wear a skirt which is socially expected in a formal event. Participants were asked to imagine Denise dressed in male's style in a very formal event. Participants gossiped about Denise's dressing style. Participants also took turns to play the role of Denise and experienced the feeling of being gossiped about.

Denise was having argument with parent(s) regarding the event. After the formal event, Denise's mother was not happy about Denise dressed in male style. Participants worked in pairs to play the role of Denise and Denise's mother. Participants had freedom to decide the personality of the role.

Denise was surprised to learn that she was an intersex because of delayed puberty. Denise was described at the age of 12 to 13 but there was no sign of menstruation. Denise went to see a doctor with her parents. In this scene, facilitator played the role of doctor and confirmed that Denise was an intersex. Participants played the role of Denise and each of them performed a few individual still images when they heard the news.

Denise tried to disclose her news to her closest friend, Jenny. Participants worked in pairs, one played the role of Denise and the other played the role of Jenny. Denise needed to decide whether she wanted to disclose the news about her status to Jenny.

Denise's family discussed the medical treatment without Denise's consensus. Three participants volunteered to play the role of Denise's father, mother and grandmother who secretly decided if they wanted to follow doctor instruction to offer Denise hormone medicine. The only requirement was that one of them had to have an opposite opinion. These three volunteers improvised the scene.

Denise engaged in an argument with her mother after discovering her hormone medicine. Participants could jointly play the role of Denise and talked to her mother. Facilitator, through the role of Denise's mother, shared her worries, and concerns about Denise's status. These information motivated participants to think the intersex issues from parental and societal perspective.

The death of Denise. All participants silently experienced the role of Denise, especially when she was forced to take hormone medicine without a choice. The scene ended by facilitator narrating that Denise was 
depressed and committed suicide a few years later.

Reflective exercise. The reflective exercise was planned for each workshop to help participants consolidating the learning experience (Clifford \& Herrmann, 1999). The technique of Image Theatre was employed to explore social oppression of intersex people from a macro perspective. Participants were divided into groups of three to four. One of them played the role of Denise, who was being oppressed because of the ambiguous sex identity. Other members of the team played the role of oppressors, which could be a person or abstract ideology. Facilitator subsequently adopted a convention called Transitional Image (Boal, 1995). Participant slowly changed from the oppressional image to an ideal image through improvisation. Based on the inspiration from the improvised movement, participants then discussed the elements were needed to change the oppressed situation of an intersex.

\section{Quantitative Measurement}

The attitude toward the intersexed scale. It is a 24-item scale with the Cronbach's coefficient alpha 0.933 and significant test-retest reliability, $p=0.01$ (McQueen, 2008). It includes 21 items such as "I would be uncomfortable around a man who had an extra female chromosome (XXY) and protruding breasts”, etc., and 3 reverse items like "I would have no problem with my brother marrying a person who was identified as female at birth and who had male chromosomes (XY)”. In a 5-point Likert scale, participants rated each item from strongly agree to strongly disagree. The higher the mark indicates the more positive attitudes towards intersexuality.

Demographic characteristic. Information includes gender, sexual orientation, age, field of occupation, educational level, marital relationship, religious identity and level of knowledge about intersexuality.

\section{Focus Group Interview}

In order to understand the extent to which the training workshop improves participants' attitudes towards intersexuality, a one-hour focus group was conducted after the completion of the workshop. The interview guideline was based on three dimensions: (1) attitudes towards intersexuality before the training workshop; (2) changes in attitudes after the workshop; and (3) additional elements that may improve their confidence and comfortability in dealing with individuals with intersex status in their work settings.

\section{Results}

\section{Quantitative Measurement}

Demographic characteristics. In total, 16 females and two males completed the questionnaires, with the mean age of $26.44 \pm 8.21$. Most of the participants identified themselves as non-believers $(N=15,83.3 \%)$. The majority of participants were heterosexual $(N=12,66.7 \%)$ whilst the rest identified themselves as homosexual $(N=1)$, bisexual $(N=4)$, or asexual $(N=1)$. Descriptive analyses suggested that the attitudes towards intersexuality before the workshop did not differ due to education level, religion and age. However, heterosexual individuals predominantly carried less positive attitudes towards intersexuality than individuals with other sexual orientations, $t_{(17)}=-2.934, p=0.01$.

Attitudes change towards intersexuality. A pair-sample $t$-test was adopted to investigate the effectiveness of the training workshop in improving participants' attitudes towards intersexuality, with results indicating that the attitudes towards intersexuality significantly improved, $t_{(17)}=-4.004, p=0.001$ (pre-test $=$ $95.17 \pm$ 10.66; post-test $=103.11 \pm 9.59$ ).

\section{Focus Group Interview}


In total, nine females and one male from the professionals of social work (SW) and education (ED) were interviewed. Based on guideline of utilizing thematic analysis (Braun \& Clarke, 2006), the recurrent themes were classified into three categories.

Prior attending the training workshop. None of the informants indicated any personal experience in coming across individuals with intersex. However, two could name a public figure who openly declared their intersexuality. A woman (with a SW background) said, "I had only heard of the term "intersex" just now. I cannot say I have any positive or negative attitudes", whilst another female (SW) stated, "I think it is either a very rare condition or they (individuals with intersex status) prefer to keep secret, I have never heard of any of my friends or my cases mention it”. Informants were asked to imagine how they would react if they encounter a person with intersex had they never attended the workshop, to which most stated that their first encounter will most likely be of shock and uncertainty. A woman (ED) shared, "I can imagine myself having initial shock, and the other person may able to tell from my facial expression and body gesture". When asked what would be in their mind in the first encounter, a woman (SW) expressed, "After the initial shock, my mind will start imagining how do the private parts (genitals) would look like for people with intersex, but I wouldn’t know what to say to that person".

Attitude change after the workshop. Completing the training workshop brought knowledge improvement and attitude change among most of the informants. One man (SW) stated, "I am surprised on the prevalence rate of intersex. It means it is likely there is one or two of my friends that are born with intersex status", whereas a female (ED) said, "I reckon my initial shock will disappear. And I will be more certain of what to say next”. Some informants claimed that they were more attentive to the needs of intersex as well as their family members. One man (SW) stated, "Now I know how hard it is for the parents to make decisions for the intersex child, this is something I didn't think of before”. Moreover, few of the informants expressed the improvement in their competence in dealing with individuals with intersex status. A woman (ED) indicated, "At least I can tell him/her it is not as rare as we think. I think normalizing the condition may be helpful", whilst a woman (SW) said, "I am more comfortable in asking them about the physical conditions and their feelings of themselves”.

Possible improvement. By far, the most recurring themes in relation to possible improvement of the training workshop are the comprehensiveness of knowledge enhancement and practice guidance towards addressing intersexuality. Two women (SW) talked about the importance of knowledge enhancement, "I reckon more medical knowledge should be involved... I am now still pretty ignorant" and "improving my understanding on the physical conditions will help me to communicate better with clients, at least I know what are the right questions to ask”. Personal sharing from intersex individual is much desired, a woman (SW) said, "It is better if I can actually hear it from a real person about their experience. So far it is us who imagine how they feel”. On the other hand, few people pressed the significance of including ethical concerns in practices and clinical guideline in dealing with intersexuality in their work settings. One woman (ED) stated, “I don't think I am equipped enough to understand the true struggles of intersex people, the ethical dilemma their family members are facing", whereas a woman (SW) said, "I am eager to learn from people who have worked with intersex cases, it will be beneficial to me to know how they normally conduct in a counseling setting”.

\section{Discussions and Conclusion}

The current study provided preliminary evidence to support the effectiveness of the use of applied theatre. 
Participants showed significant enhancement in positive attitudes towards intersexuality after the workshops. The experience enhanced learning in two perspectives. First, it created sympathy by connecting participants' emotions to the emotions of the characters in the story. The empathy created and facilitated a deep reflection on their possible action. Second, it created a sense of lack of information, thus motivated participants to acquire more knowledge by themselves. Unlike traditional forms of education approach, the workshop tended to engage students emotionally more than intellectually. The results found in focus group interview showed that engaging learners' emotion in the learning process has helped them to prepare the experience in the future and motivate them to acquire related knowledge by themselves. These findings also support John Dewey's argument in his book Art as Experience (Dewey, 1934) which suggested that the learning experience with aesthetic experience and emotions engagement leads to a complete learning experience.

Emotions provoked by body movement could enhance reflections on the issue. At the very beginning of the workshop, most of the participants did not know much about the issue of intersex. The facilitator had briefly described intersex as a person who cannot be easily identified as a male or female base on chromosomes or sex organs but not any other additional information. The workshop started with engaging participants with their body and physical movement through acting the characters in the story (O’Toole, 1992). Through the acting process, participants were encouraged to step into the shoes of the intersex and experienced the hardship of discovering the ambiguous sex identity of one self. Participants were not taught what to do in the character but acted base on their own experience and understanding. This process facilitated participants to experience subjectively with their emotions (Garrison, 2012), thus connected their own feeling and needs to the emotion of an intersex, friends and family members of an intersex.

They also experienced the sense of shock when being told by an intersex friend about their exceptional sex conditions. Having this initial experience of feeling shock served as a rehearsal to some participants, which prepared them to be more ready to response if they encounter similar incident in the future. Also, the sensation and sympathy created through the process has triggered them to reflect more about an appropriate response to an intersex person.

Furthermore, the workshop motivated participants to actively acquire more knowledge about the issue. The drama process heavily relied on participants' reaction to the incidents happened in the story. However, most of the participants did not have advanced knowledge while they are participating. Some of them were astonished by their ignorance in the issue of intersex in the process. The sense of ignorance drives their eagerness to learn more. This is an approach almost opposite to traditional classroom teaching.

A scholar of critical pedagogy, Paulo Freire, used the analogy of banking system to describe the mainstream education system (Freire, 2003). Teachers considered themselves as knowledgeable, whereas learners have no knowledge about the subject. This attitude of education considered teacher as if they were knowledge messenger of the subject. Their objective was to "deposit" knowledge to the learners' "bank account”. In contrast, the drama process changed the role of the teacher from a knowledge messenger to a facilitator. Freire called this approach as "problem-posing” (Freire, 2003, p. 64). In the drama workshop, participants experienced the scenarios created by the facilitator. The process continuously unveils problems to another levels and discovering new perspectives. For instance, most of them firstly developed compassion towards Denise and believed Denise's mother was immoral to give her hormone medicine without her consent. However, through facilitator-in-role, Denise's mother explained the dilemma of the decision. Denise's mother explained that she wanted to respect Denise's decision but she also thought giving her hormone medicine was 
an act of protecting her from social discrimination. Participants' learning was manifested in the reflective exercise, many of them did not blamed Denise's mother as an oppressor of an intersex. Instead, most of them blamed the socially constructed concept of binary gender. The new discoveries happened in the process made them to recognize that they knew very little, therefore they attempted to reflect deeper and also strived to learn more (Roberts, 2000).

However, not being able to trace participants' follow-up learning action after the workshop was one of the limitations of this approach. Although some of them showed interested in learning more about intersex in the focus group interview, it would be interesting to find out how many of them have actually initiated the self-learning process afterwards, and how deep the knowledge they have acquired.

More importantly, from the preliminary findings resulting of this pilot study, it shows that knowledge and competence in dealing with intersex are grossly underdeveloped among helping professionals in Hong Kong Chinese. Seeing that people born with intersex conditions can experience trauma and stigma, current intervention and practice protocols do not acknowledge, let alone, adequately address the needs of people with intersex conditions, and their families. Hong Kong is lagging far behind other developed nations in recognizing the rights of individuals with intersex conditions and as such, perpetuates the silence of these individuals and their inability to come forward to receive social services and resources.

Recently, the Advisory Group on Eliminating Discrimination against Sexual Minorities (The Advisory Group) was established in June 2013 by the Constitutional and Mainland Affairs Bureau, Hong Kong. The advisory report, submitted in December 31, 2015, emphasized that the discrimination act experienced by sexual minorities, including lesbians, gays, bisexuals, transgender people, post-gays and intersex persons, is due to the "lacked sensitivity in relation to issues related to sexual orientation and gender identity" (Advisory Group on Eliminating Discrimination against Sexual Minorities, 2015, p.2). Similar finding was revealed by a study conducted by Equal Opportunities Commission (EOC), sexual minorities expressed that "In the extreme cases, teachers, counsellors and social workers were perceived to be the perpetrators of discrimination” (Equal Opportunities Commission, 2016, p. 85). To this end, recommendation issued by the Advisory Group stated that "training and resources with focus on sensitivity towards sexual minorities for teachers; medical practitioners, associated professionals and frontline workers in hospitals and clinics; social workers; and human resources professionals... as the professional groups having more direct interactions with sexual minorities, which should also be promoted and introduced to employees of the Government” (Advisory Group on Eliminating Discrimination against Sexual Minorities, 2015, p. 3). In light of this dearth of knowledge and practice guideline, the current finding can be used to develop a training program that aims to equip frontline practitioners, including social workers and teachers, to address the need of individuals with intersex status.

\section{Reflection From an Applied Theatre Practitioner Prospective}

As an applied theatre practitioner, the choice of using applied theatre as pedagogy is aiming at achieving an educational outcome which is not achievable through one-way lecturing. Preparation time for a six-hour drama session is more time-consuming then a one hour lecture. Also, comparing to a one-way lecturing, a drama workshop usually can only benefit a comparatively smaller number of population. It can be seen as a waste of time and resources, however, the use of drama as a pedagogy achieve a different learning outcome as compare to traditional teaching approaches.

The research findings in this pilot study reassured that interactive theatre engages participants not only 
intellectually but emotionally. Not only did participants gain knowledge of the issue, but also developed sympathy to intersex people, their family and friends. In the other words, applied theatre as a pedagogy leads to a more complete learning experience (Dewey, 1934). The dramatic experience also triggers the participants to reflect deeper and to strive to learn more.

Apart from the effectiveness of the interactive teaching approach, it will also be worthwhile to understand how to foster participants translating the reflection on the issue of intersex to a wider social context. As mentioned earlier, the oppression of intersex people is the deep-rooted belief and stereotype of gender binary, which classified human being into two distinct forms of male and female. The story of intersex would be a good starting point to provoke a deeper reflection on the gender stereotype that we are consciously or unconsciously contributing to. The reflective exercise in the workshop could be a good bridge between the understandings of intersex to the reflection on the rigid gender binary system. The reflective session directed participants to reflect on oppression encountered by intersex people in general. After examining how gender oppression executed in the society, they can further reflect how the gender oppression operates to all human beings.

\section{Conclusion}

In conclusion, to promote a stigma-free society, developing people sensitivity on gender stereotype and be more empathetic and acceptance to neglected population would be an essential starting point. The findings of this pilot study demonstrated that applied drama could be one of the useful pedagogic tools. The finding of this study will be an important step of initiating discussion in Chinese communities with the ultimate purpose of putting forward cultural-sensitive advocacy movement, enriching the competence training for frontline professionals and forming counselling guidelines for this silent and underrepresented population group in Chinese communities.

\section{References}

Advisory Group on Eliminating Discrimination against Sexual Minorities. (2015). Executive summary of the report of the advisory group: Constitutional and mainland affairs bureau, HKSAR. Retrieved from http://www.cmab.gov.hk/doc/issues/executive_summary_e.pdf

Blackless, M., Charuvastra, A., Derryck, A., Fausto-Sterling, A., Lauzanne, K., \& Lee, E. (2000). How sexually dimorphic are we? Review and synthesis. American Journal of Human Biology, 12(2), 151-166.

Boal, A. (1995). The rainbow of desire: The Boal method of theatre and therapy. London and New York: Routledge.

Boal, A. (2008). Theatre of the oppressed (New ed.). London: Pluto Press.

Braun, V., \& Clarke, V. (2006). Using thematic analysis in psychology. Qualitative Research in Psychology, 3(2), 77-101.

Bundy, P., \& Dunn, J. (2006). Pretexts and possibilities. The Journal of the Queensland Association for Drama in Education: Drama Queensland Says, 29(2), 19-21.

Butler, J. (2004). Undiagnosing gender. In Undoing Gender (pp. 75-101). London and New York: Routledge.

Châtelet, N. (2003). La tête en bas: Roman. Paris: Seuil.

Clifford, S., \& Herrmann, A. (1999). Making a leap: Theatre of empowerment: A practical handbook for drama and theatre work with young people. London and Philadelphia: Jessica Kingsley Publishers.

Creighton, S. M., \& Liao, L. M. (2004). Changing attitudes to sex assignment in intersex. BJU International, 93(5), 659-664. Retrieved from 10.1111/j.1464-410X.2003.04694.X

DeFrancisco, V. P., \& Palczewski, C. H. (2007). Communicating gender diversity: A critical approach. Sage Publications.

Dewey, J. (1934) [1980]. Art as experience. New York, NY: Perigee Books.

Equal Opportunities Commission. (2016). Report on study on legislation against discrimination on the grounds of sexual orientation, gender identity and intersex status. Equal Opportunities Commission, HKSAR. Retrieved from 
http://www.eoc.org.hk/eoc/upload/ResearchReport/20161251750293418312.pdf

Freire, P. (2003). From pedagogy of the oppressed. In A. Darder, M. Baltodano, \& R. D. Torres (Eds.), The critical pedagogy reader (pp. 57-98). New York, NY: RoutledgeFalmer.

Garrison, J. (2012). John Dewey’s philosophy of education: An introduction and recontextualization for our times. New York, NY: Palgrave Macmillan.

International Lesbian Gay Bisexual Trans and Intersex Association. (2010). 2010 Annual Report. Retrieved January 26, 2016, from http://old.ilga.org/documents/ILGA_Annual_Report_2010.pdf

Jennings, S. (Ed.). (1987). Drama therapy. London and New York: Routledge.

McQueen, K. S. (2008). The Development of the Attitudes toward the Atypically gendered Inventory (ATAG-I) (Unpublished Doctoral dissertation, Indiana University, Indiana, United States).

O'Neill, C. (1995). Drama worlds: A framework for process drama. Portsmouth, NH: Heinemann.

O’Toole, J. (1992). The process of drama. London and New York: Routledge.

O’Toole, J., \& Dunn, J. (2002). Pretending to learn. Sydney: Pearson Education.

Prentki, T., \& Preston, S. (2009). Applied theatre: An introduction. In T. Prentki, \& S. Preston (Eds.), The applied theatre reader (pp. 9-15). London and New York: Routledge.

Roberts, P. (2000). Education, literacy, \& humanization: An introduction to the work of Paulo Freire. Westport: Greenwood Press.

United Nation Human Rights Council. (2013). Report of the Special Rapporteur on torture and other cruel, inhuman or degrading treatment or punishment. Geneva. Retrieved from http://www.ohchr.org/documents/hrbodies/hrcouncil/ regularsession/session22/a.hrc.22.53_english.pdf 